\title{
A Framework for Life Cycle Sustainability Assessment of Road Salt Used in Winter Maintenance Operations
}
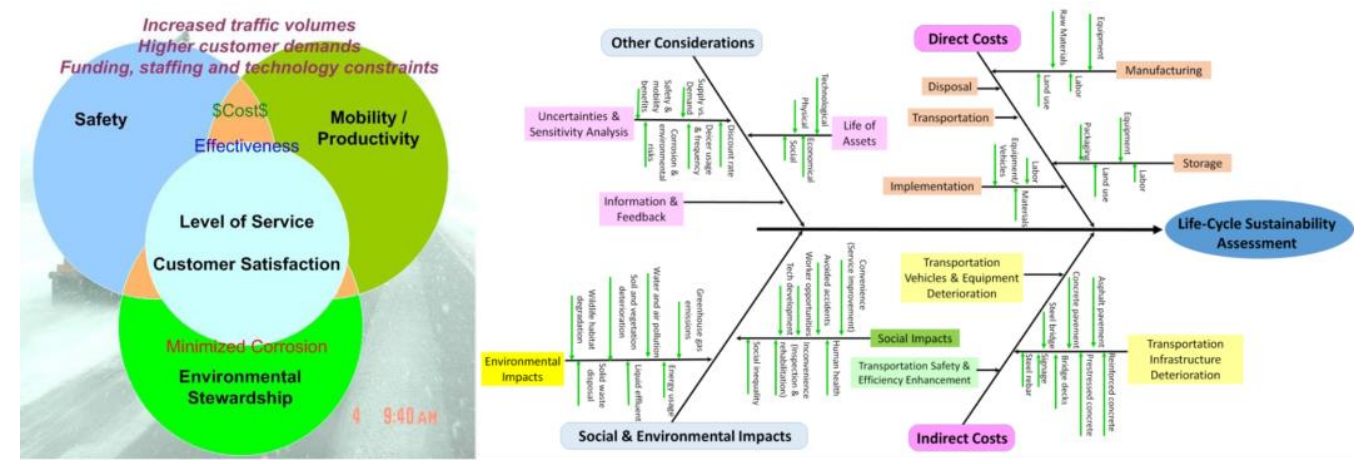

Prepared by:

Na Cui, Ph.D., and Ning Xie, Ph.D.

Western Transportation Institute, Montana State University

Xianming Shi, Ph.D., P.E.

Washington State University

December 2016

Prepared for:

Center for Environmentally Sustainable U.S. Department of Transportation Transportation in Cold Climates

University of Alaska Fairbanks 1200 New Jersey Avenue, SE

P.O. Box 755900

Washington, DC 20590

Fairbanks, AK 99775

INE/AUTC 17.04
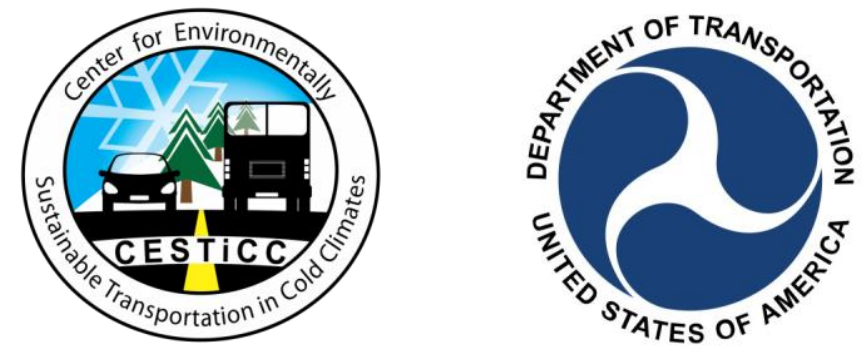


\section{REPORT DOCUMENTATION PAGE}

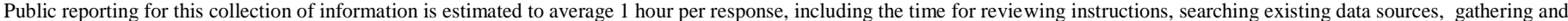

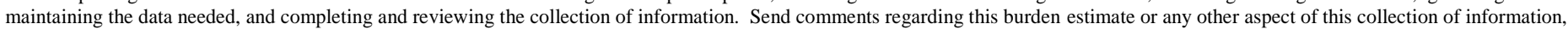

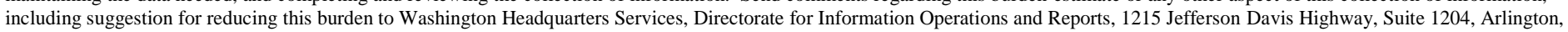
VA 22202-4302, and to the Office of Management and Budget, Paperwork Reduction Project (0704-1833), Washington, DC 20503

\section{\begin{tabular}{|l|l|l}
\hline 1. AGENCY USE ONLY (LEAVE BLANK) & 2. REPORT DATE & 3. REPORT TYPE AND DATES COVERED
\end{tabular}}

$12 / 2016$

Final Report: 10/2014 - 12/2016

\section{TITLE AND SUBTITLE}

A Framework for Life Cycle Sustainability Assessment of Road Salt Used in Winter

Maintenance Operations

6. AUTHOR(S)

Name, Title, Organization/University

Na Cui, Ning Xie, and Xianming Shi

7. PERFORMING ORGANIZATION NAME(S) AND ADDRESS(ES)

Center for Environmentally Sustainable Transportation in Cold Climates

University of Alaska Fairbanks

5. FUNDING NUMBERS

INE/CESTiCC 101403

Duckering Building Room 245

P.O. Box 755900

Fairbanks, AK 99775-5900

9. SPONSORING/MONITORING AGENCY NAME(S) AND ADDRESS(ES)

U.S. Department of Transportation

1200 New Jersey Avenue, SE

Washington, DC 20590

11. SUPPLENMENTARY NOTES

12a. DISTRIBUTION / AVAILABILITY STATEMENT

12b. DISTRIBUTION CODE

No restrictions

\section{ABSTRACT (Maximum 200 words)}

It is important to assess from a holistic perspective the sustainability of road salt widely used in winter road maintenance (WRM) operations. The importance becomes increasingly apparent in light of competing priorities faced by roadway agencies, the need for collaborative decision-making, and growing concerns over the risks that road salt poses for motor vehicles, transportation infrastructure, and the natural environment. This project introduces the concept of Life Cycle Sustainability Assessment (LCSA), which combines Life Cycle Costing, Environmental Life Cycle Assessment, and Social Life Cycle Assessment. The combination captures the features of three pillars in sustainability: economic development, environmental preservation, and social progress. With this framework, it is possible to enable more informed and balanced decisions by considering the entire life cycle of road salt and accounting for the indirect impacts of applying road salt for snow and ice control. This project proposes a LCSA framework of road salt, which examines the three branches of LCSA, their relationships in the integrated framework, and the complexities and caveats in the LCSA. While this framework is a first step in the right direction, we envision that it will be improved and enriched by continued research and may serve as a template for the LCSA of other WRM products, technologies, and practices.

14- KEYWORDS :

winter road maintenance; road salt; sustainability analysis; life cycle assessment

15. NUMBER OF PAGES

\begin{tabular}{|l|l|l|}
\multicolumn{2}{|l|}{} \\
$\begin{array}{l}\text { 17. SECURITY CLASSIFICATION OF } \\
\text { REPORT }\end{array}$ & $\begin{array}{l}\text { 18. SECURITY CLASSIFICATION } \\
\text { OF THIS PAGE }\end{array}$ & $\begin{array}{l}\text { 19. SECURITY CLASSIFICATION } \\
\text { OF ABSTRACT }\end{array}$ \\
\multicolumn{1}{|c|}{ Unclassified } & \multicolumn{1}{c|}{ Unclassified } \\
\hline
\end{tabular}




\title{
A FRAMEWORK FOR LIFE CYCLE SUSTAINABILITY ASSESSMENT OF ROAD SALT USED IN WINTER \\ MAINTENANCE OPERATIONS
}

\author{
FINAL REPORT
}

Prepared for

Center for Environmentally Sustainable Transportation in Cold Climates

\author{
Authors: \\ Na Cui, Ph.D., and Ning Xie, Ph.D. \\ Montana State University \\ Western Transportation Institute \\ Xianming Shi, Ph.D., P.E. \\ Washington State University \\ Department of Civil and Environmental Engineering
}

INE/AUTC 17.04

December 2016 


\section{DISCLAIMER}

This document is disseminated under the sponsorship of the U.S. Department of Transportation in the interest of information exchange. The U.S. Government assumes no liability for the use of the information contained in this document. The U.S. Government does not endorse products or manufacturers. Trademarks or manufacturers' names appear in this report only because they are considered essential to the objective of the document. Opinions and conclusions expressed or implied in the report are those of the author(s). They are not necessarily those of the funding agencies. 
METRIC (SI*) CONVERSION FACTORS

APPROXIMATE CONVERSIONS TO SI UNITS

\begin{tabular}{|c|c|c|c|c|c|c|c|c|c|}
\hline Symbol & When You Know & Multiply By & To Find & Symbol & Symbol & When You Know & $\begin{array}{c}\text { Multiply } \\
\text { By }\end{array}$ & To Find & Symbol \\
\hline & & LENGTH & & & & & LENGTH & & \\
\hline in & inches & 25.4 & & $\mathrm{~mm}$ & $\mathrm{~mm}$ & millimeters & 0.039 & inches & in \\
\hline $\mathrm{ft}$ & feet & 0.3048 & & $\mathrm{~m}$ & & meters & 3.28 & feet & $\mathrm{ft}$ \\
\hline $\mathrm{yd}$ & yards & 0.914 & & $\mathrm{~m}$ & $\mathrm{~m}$ & meters & 1.09 & yards & yd \\
\hline $\mathrm{mi}$ & Miles (statute) & 1.61 & & $\mathrm{~km}$ & $\mathrm{~km}$ & kilometers & 0.621 & Miles (statute) & $\mathrm{mi}$ \\
\hline & & AREA & & & & & AREA & & \\
\hline $\mathrm{in}^{2}$ & square inches & 645.2 & millimeters squared & $\mathrm{cm}^{2}$ & $\mathrm{~mm}^{2}$ & millimeters squared & 0.0016 & square inches & in $^{2}$ \\
\hline $\mathrm{ft}^{2}$ & square feet & 0.0929 & meters squared & $\mathrm{m}^{2}$ & $\mathrm{~m}^{2}$ & meters squared & 10.764 & square feet & $\mathrm{ft}^{2}$ \\
\hline $\mathrm{yd}^{2}$ & square yards & 0.836 & meters squared & $\mathrm{m}^{2}$ & $\mathrm{~km}^{2}$ & kilometers squared & 0.39 & square miles & $\mathrm{mi}^{2}$ \\
\hline $\mathrm{mi}^{2}$ & square miles & 2.59 & kilometers squared & $\mathrm{km}^{2}$ & ha & hectares $\left(10,000 \mathrm{~m}^{2}\right)$ & 2.471 & acres & ac \\
\hline ac & acres & 0.4046 & hectares & ha & & & & & \\
\hline & & $\begin{array}{c}\text { MASS } \\
\text { (weight) }\end{array}$ & & & & & $\begin{array}{l}\text { MASS } \\
\text { (weight) }\end{array}$ & & \\
\hline $\mathrm{oz}$ & Ounces (avdp) & 28.35 & grams & $\mathrm{g}$ & $\mathrm{g}$ & grams & 0.0353 & Ounces (avdp) & $\mathrm{OZ}$ \\
\hline $\mathrm{lb}$ & Pounds (avdp) & 0.454 & kilograms & $\mathrm{kg}$ & $\mathrm{kg}$ & kilograms & 2.205 & Pounds (avdp) & $\mathrm{lb}$ \\
\hline $\mathrm{T}$ & Short tons $(2000 \mathrm{lb})$ & 0.907 & megagrams & $\mathrm{mg}$ & $\mathrm{mg}$ & megagrams (1000 kg) & 1.103 & short tons & $\mathrm{T}$ \\
\hline & & VOLUME & & & & & VOLUME & & \\
\hline $\mathrm{fl} \mathrm{oz}$ & fluid ounces (US) & 29.57 & milliliters & $\mathrm{mL}$ & $\mathrm{mL}$ & milliliters & 0.034 & fluid ounces (US) & $\mathrm{fl} \mathrm{oz}$ \\
\hline gal & Gallons (liq) & 3.785 & liters & liters & liters & liters & 0.264 & Gallons (liq) & gal \\
\hline $\mathrm{ft}^{3}$ & cubic feet & 0.0283 & meters cubed & $\mathrm{m}^{3}$ & $\mathrm{~m}^{3}$ & meters cubed & 35.315 & cubic feet & $\mathrm{ft}^{3}$ \\
\hline $\mathrm{yd}^{3}$ & cubic yards & 0.765 & meters cubed & $\mathrm{m}^{3}$ & $\mathrm{~m}^{3}$ & meters cubed & 1.308 & cubic yards & $\mathrm{yd}^{3}$ \\
\hline
\end{tabular}

Note: Volumes greater than $1000 \mathrm{~L}$ shall be shown in $\mathrm{m}^{3}$

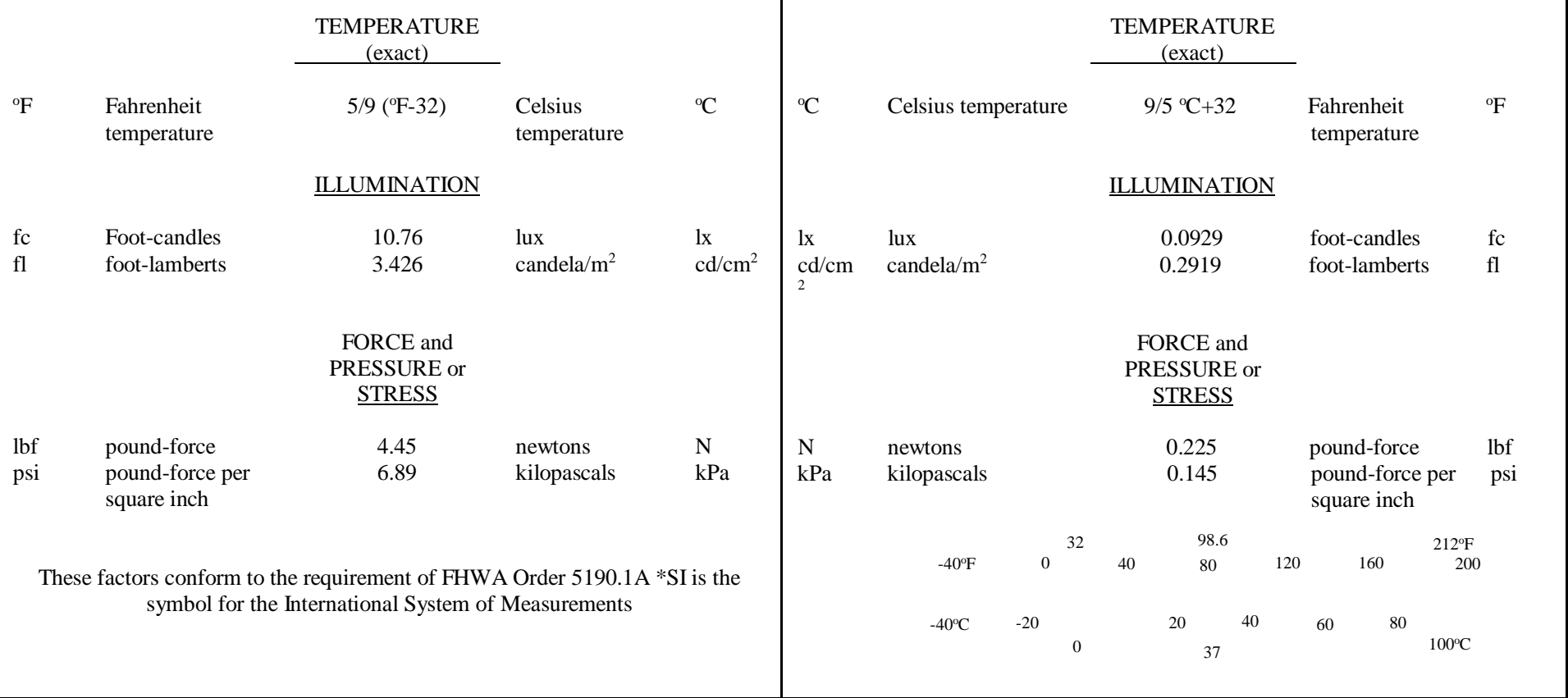




\section{ACKNOWLEDGMENTS}

The authors wish to express their appreciation to the Center for Environmentally Sustainable Transportation in Cold Climates (CESTiCC) for its support throughout this study. The authors would also like to thank all members of the Project Technical Advisory Committee. Acknowledgment is extended to the National Natural Science Foundation of China through Project 71403069, and the Postdoctoral Science Foundation of China through Grant 2014M551261 and 2015T80361 for partial support for this study. 


\section{TABLE OF CONTENTS}

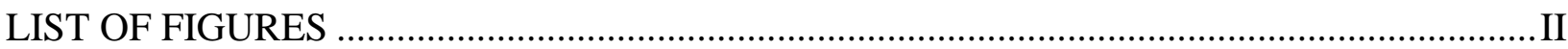

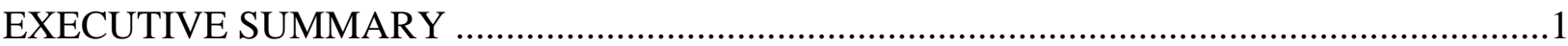

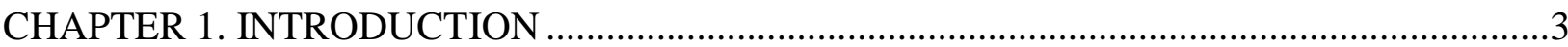

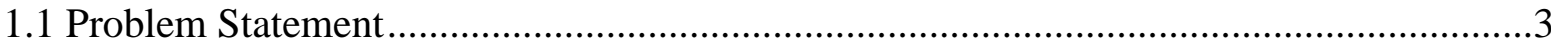

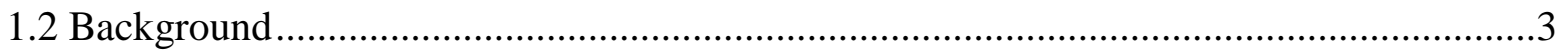

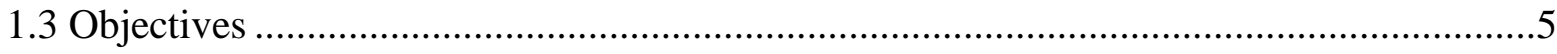

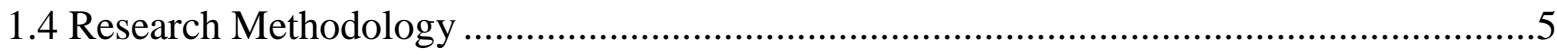

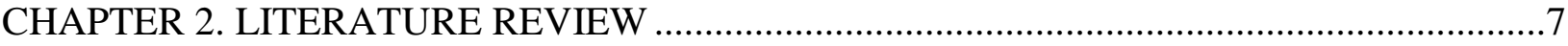

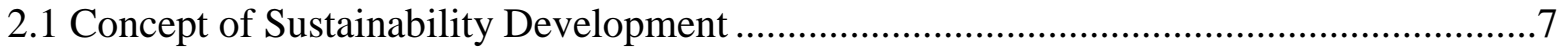

2.2 Highway Winter Maintenance: Current Practices ........................................................13

2.3 Complexities and Caveats in the LCSA of Road Salt ................................................15

CHAPTER 3. METHODOLOGY - CONCEPTS OF LIFE CYCLE SUSTAINABILITY

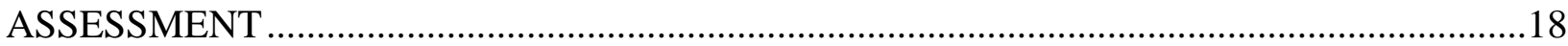

CHAPTER 4. A PRELIMINARY LCSA FRAMEWORK OF ROAD SALT ...........................22

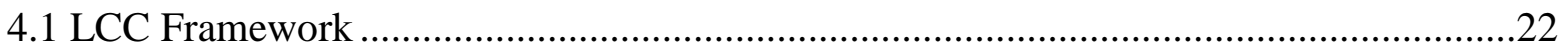

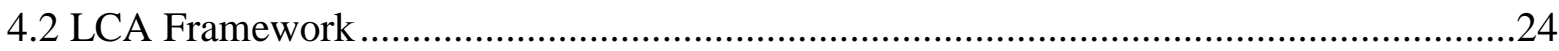

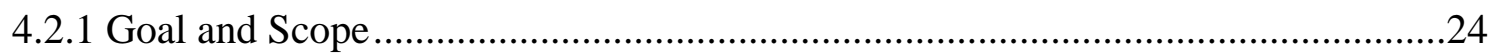

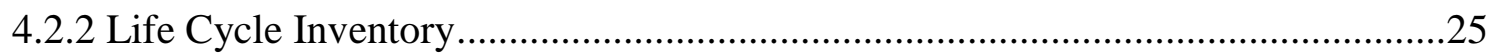

4.2.3 Life Cycle Impact Assessment ........................................................................25

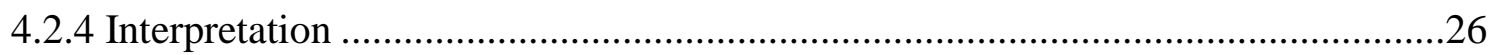

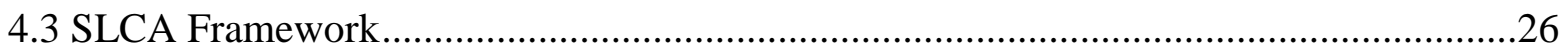

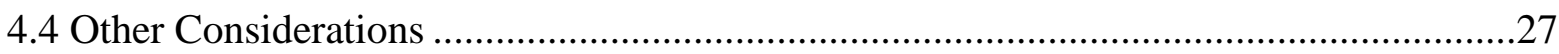

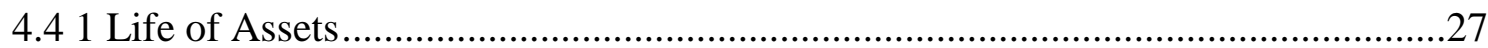

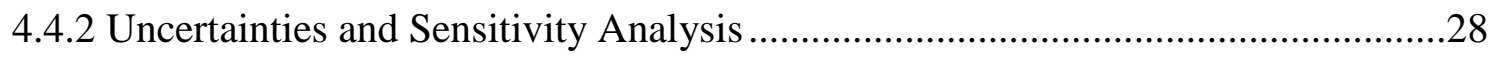

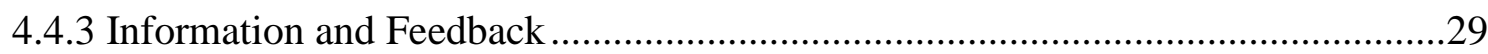

4.5 The Relationships of LCC, LCA, and SLCA in the LCSA ........................................29

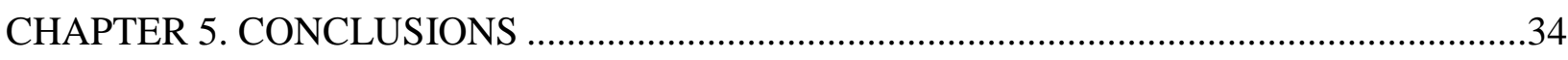

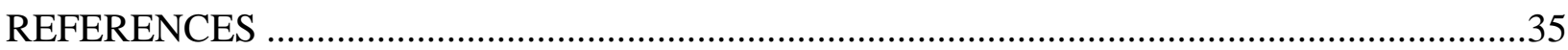




\section{LIST OF FIGURES}

Figure 2.1 Three-dimensional framework of a sustainability development concept

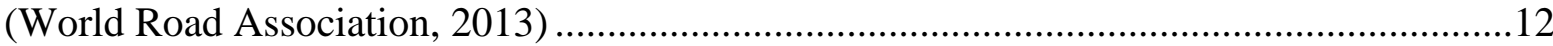

Figure 2.2 The concept of sustainable winter roadway maintenance (Shi, 2010) ......................13

Figure 3.1 Harvey's LCC procedure (Harvey, 1976; Woodward, 1997) ....................................19

Figure 3.2 LCA framework based on the ISO 14040 standard.............................................19

Figure 3.3 Five simplified stakeholder categories in the production system, according

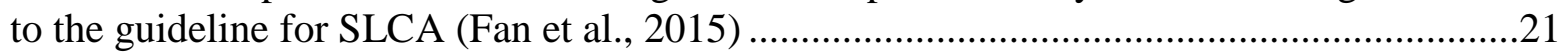

Figure 4.1 Interactions between LCC, LCA, SLCA, and LCSA ..............................................30

Figure 4.2 The interactions considered in the LCSA process ....................................................32

Figure 4.3 LCSA fishbone diagram of road salt used in WRM operations ..................................33 


\section{EXECUTIVE SUMMARY}

Because of the negative impacts that snow- and ice-control products have on the natural environment, on transportation infrastructure, and on motor vehicles, it is necessary to adopt sustainability principles for winter road maintenance (WRM) operations, to ensure that any cost savings from winter maintenance practices are not at the expense of infrastructure strength, environmental health, or traveler safety.

In this study, road salt (the most commonly used deicer for winter maintenance antiicing, deicing, and pre-wetting practices) was the research starting point. Applying the principles of sustainability to the "triple bottom line" - economy, environment, and societywe considered not only the economic savings and benefits from enhanced winter roadway safety and mobility, but also the indirect costs resulting from issues such as infrastructure degradation and vehicle corrosion. Since an environmental footprint of WRM operations is possible at any step of the production, distribution, storage, and application of snow- and icecontrol products, this study introduced the concept of Life Cycle Sustainability Assessment (LCSA), an examination of the entire life cycle of road salt deicers, the cradle-to-grave effects. Features of the three pillars of sustainability (economic development, environmental preservation, and social progress) were captured, respectively, by the three branches of LCSA: life cycle costing, environmental life cycle assessment, and social life cycle assessment. This endeavor reflects the current state of thinking as regards the LCSA of road salt, including the concepts, factors, and considerations of the three branches of LCSA, their relationships in the integrated framework, and the complexities and caveats related to LCSA.

With this framework, it is possible to enable better informed and balanced decisions and account for the indirect impacts of applying road salt for snow and ice control. While this framework is a first step in the right direction, we envision that it will be improved and 
enriched by continued research and may serve as a template for the LCSA of other WRM products, technologies, and practices. 


\section{CHAPTER 1. INTRODUCTION}

\section{$\underline{1.1 \text { Problem Statement }}$}

One of the basic requirements of successfully implementing a winter road maintenance (WRM) program is the appropriate selection of deicers (Shi et al., 2013). Traditionally, nominal cost and effectiveness were the main criteria used by roadway professionals when making such a selection. However, there is growing concern over the negative impacts of such chemicals on the natural environment (Levelton Consultants, 2007; Corsi et al., 2010; Fay and Shi, 2012), transportation infrastructure (Pan et al., 2008; Shi et al., 2010; Xie et al., 2016), and motor vehicles (Shi et al., 2009; Dean et al., 2012). To address these risks, researchers have sought alternatives to regular road salt, for example, agro-based and complex chlorides/minerals-based products (Hossain et al., 2015; Muthumani and Shi, 2016). The search for deicer alternatives has triggered the need for sustainability principles for WRM operations, to ensure that any cost savings in winter maintenance practices are not at the expense of infrastructure strength, environmental health, or traveler safety.

\section{$\underline{1.2 \text { Background }}$}

The principles of sustainability generally put emphasis on the "triple bottom line," economy, environment, and society, and these principles have yet to be applied to WRM operations. Over the past decade, addressing sustainability in WRM operations has attracted more attention (Nixon, 2012). In assessing the life cycle sustainability of chloride-based deicers for WRM operations, it is not sufficient to estimate only the economic savings from enhanced winter roadway safety and mobility; the indirect costs of infrastructure degradation, vehicle corrosion, etc., must be considered as well. Efforts should be made to quantify the life cycle footprint of each deicer on the natural environment and on society. Note that many of 
the costs (or benefits), environmental impacts, and social impacts can be intangible, hard to quantify, and inherently stochastic, making it difficult to conduct a reliable life cycle sustainability assessment (LCSA).

Since a consensus has been reached that the principles of sustainability should guide all transportation designs and operations, a variety of relevant efforts have been made to adopt them in WRM operations. One example of these efforts is the development of a practical web-based collection of best practices by the U.S. Federal Highway Administration (FHWA), aimed at assisting state departments of transportation (DOTs) with integrating sustainability into their practices in managing transportation systems. Another FHWA tool, INVEST (Infrastructure Voluntary Evaluation Sustainability Tool), provides a segment on winter maintenance, including a road weather information system (RWIS), a materials management plan, and a maintenance decision support system (MDSS), and shows the implementation of standards of practice for snow and ice control (Shi et al., 2013). These efforts have been useful in promoting sustainability in WRM operations, but do not provide a framework for enabling reliable quantification of life cycle sustainability of deicers or other WRM practices.

Multiple dimensions of deicer selection demand an integrated sustainability assessment framework, which is currently non-existent in published literature. Yet, this framework is needed by agencies before they can appropriately assess the related socialeconomic costs and benefits of a deicer and comprehensively account for its environmental impacts, thus make better informed decisions based on comparisons of different deicer products and improve their operations (Fitch et al., 2013). For instance, depending on the manufacturing and processing technique of products used for snow and ice control, the production, distribution, storage, and application of these compounds unavoidably contribute to the environmental footprint of WRM operations. The negative impacts of deicers on 
vehicles and infrastructure also induce secondary environmental impacts. Hence, it is important to consider the entire life cycle of deicers, from mining/extraction, processing, storage, distribution, and roadway application, to their eventual fate and transport in the environment, or through recycling. These considerations should be examined with a life cycle approach and a balanced perspective among all relevant stakeholders.

\section{$\underline{1.3 \text { Objectives }}$}

A LCSA framework would help produce a full picture of the impacts of each step in the use of deicers and would facilitate balanced decisions. As such, this project anatomizes the LCSA framework of road salt (the most commonly used deicer for anti-icing, deicing, and pre-wetting practices) through analyses of the triple bottom line. This research reflects the current state of thinking on the structure of the LCSA framework of road salt, including concepts, complexities and caveats, and considerations as they relate to each of the three branches of LCSA (economic, environmental, and social aspects). While this framework is a first step in the right direction, we envision that it will be improved and enriched by continued research and may serve as a template for the LCSA of other WRM products, technologies, and practices.

\section{$\underline{1.4 \text { Research Methodology }}$}

Our research plan was tailored to meet the needs of preliminary LCSA framework development for the application of road salt in WRM operations, addressing current informational gaps and challenges. The effort was accomplished through a sequential series of tasks and approaches outlined below.

\section{Task 1: Literature Review}

Task 1 involved determining the state of knowledge and best practices in highway winter maintenance, with the goal of providing a foundation for Task 2. Available literature 
was synthesized with a focus on the concept of sustainability development, practices of sustainable highway winter maintenance, as well as the complexities and caveats in the LCSA of road salt. This task is presented in Chapter 2.

\section{Task 2: Sustainability Accounting}

Because sustainability may have many dimensions in the economic, social, and environmental domains, Task 2 involved assembling the current pool of written knowledge relevant to the sustainability of winter maintenance operations from all three pillars of sustainability. Especially, the benefits (e.g., improved mobility, fewer accidents, and reduced travel cost) and the negative impacts (e.g., energy consumption, water and soil contamination, vegetation stress, infrastructure and automobile corrosion) of applying road salt were explored in this task. A comprehensive diagram was developed to show the occurrence of these costs and environmental impacts within the whole life cycle of road salt application in winter maintenance operations. This task is presented in Chapters 3 and 4 .

Task 3: Development of a Comprehensive Life Cycle Sustainability Assessment Framework

In Task 3, we drew upon sustainability accounting analysis to present a new way of evaluating highway winter maintenance strategies through a LCSA approach that integrates economic, social, and environmental considerations of sustainability in the same framework. A schematic of the primary process, steps for general treatment strategy, was examined over the entire life cycle of production, distribution, and application, to recycling. Besides the social-economic cost and benefit, various environmental factors and their negative impacts were emphasized, with a series of the index for each step. This task is presented in Chapters 3 and 4.

\section{Task 4: Final Report}

In Task 4, a final report that thoroughly details the research undertaken in addressing the project objectives was produced and submitted to the study panel for review. 


\section{CHAPTER 2. LITERATURE REVIEW}

\subsection{Concept of Sustainability Development}

Since the concept of sustainability development came to international focus in the 1990s, adopting the principles of sustainability in transportation systems has grown as an area of interest both in practical and theoretical studies, as evidenced by more governmental agencies and research organizations worldwide incorporating sustainability considerations in transportation planning and infrastructure provision. Sustainability principles are beneficial when balancing different and sometimes competing objectives in transportation projects and programs; however, no standard definition for sustainable development exists, even in the specific transportation area. Definitions of sustainability in the transportation system and its scope have been provided in many research papers (Mihelcic et al., 2003), but the concept of transportation system sustainability varied. A review of several sustainability-related projects and studies identified how sustainability is defined in the transportation system.

A famous and universal overarching definition of sustainability development was given by the Brundtland Commission in 1987: "Sustainable development meets the needs of the present without compromising the ability of future generations to meet their own needs" (World Commission on Environment and Development, 1987, P41). Many researchers interested in this topic have pointed out the difficulty of capturing the essentiality of sustainability based on the Brundtland Commission definition, partly due to its lack of detail. This definition, however, forms the bones of further definitions of sustainability in various industries, based on different needs and aspirations.

Mihelcic et al. (2003) defined sustainability as "the design of human and industrial systems to ensure that humankind's use of natural resources and cycles do not lead to diminished quality of life due either to losses in future economic opportunities or to adverse 
impacts on social conditions, human health, and the environment." The statement specifies the essential requirements to reconcile societal and economic development goals with limited environmental resources as "social conditions, economic opportunity, and environmental quality."

The NCHRP Report 577 “Guidelines for the Selection of Snow and Ice Control Materials to Mitigate Environmental Impacts" applied the sustainability concept to the field of winter highway maintenance and defined sustainable winter operations as utilizing the most appropriate snow and ice control equipment, process and materials for the unique objectives and conditions that each agency encounters in a manner that does not compromise the ability of future generations to do likewise (Levelton Consultants, 2007).

Mihyeon Jeon and Amekudzi summarized a series of respective definitions of transportation system sustainability (Mihyeon and Amekudzi, 2005). Sustainable Transportation Indicators Subcommittee of the Transportation Research Board (2008) recognized sustainable development issues to three main categories: economic, social and environmental, and some other issues such as governance and fiscal sustainability. The European Commission (Energy, Environment, and Sustainable Development Program) characterized a sustainable urban transport and land use system as one that "provides access to goods and services in an efficient way for all inhabitants of the urban area; protects the environment, cultural heritage and ecosystems for the present generation; and does not endanger the opportunities of future generations to reach at least the same welfare level as those living now, including the welfare they derive from their natural environment and cultural heritage" (European Commission, 2003; Jeon and Amekudzi, 2005, P6). The European Environment Agency (EEA, 2002) described the systemic characteristics of sustainable development as carrying capacities of the environment, or interrelations between economy, society, and environment. 
Besides providing specific definitions of sustainable development, more organizations and agencies were dedicated to defining sustainable transportation systems with a collection of itemized and general operational principles. Some typical descriptions can be found in Jeon and Amekudzi’s study as follows:

Transport Canada (2001) listed a set of principles from social, economic, environmental, and management domains to recognize sustainable development, respectively (Jeon and Amekudzi, 2005, P4).

(1) Social principles: safety and health, access and choice, quality of life; (2) Economic principles: efficiency, cost internalization, affordability; (3) Environmental principles: pollution prevention, protection and conservation, environmental stewardship: and (4) Management principles: leadership and integration, precautionary principle, consultation and public participation, accountability.

Transportation Association of Canada (1999) itemized sustainable transportation in a separate manner from environment, society, and economy aspects (Jeon and Amekudzi, 2005, P5):

(1) In the natural environment: limit emissions and waste (that pollute air, soil and water) within the urban area' ability to absorb/recycle/cleanse; provide power to vehicles from renewable or inexhaustible energy sources (such as solar power in the long run); and recycle natural resources used in vehicles and infrastructure (such as steel, plastic, etc.). (2) In society: provide equity of access for people and their goods, in this generation and for all future generations; enhance human health; help support the highest quality of life compatible with available wealth; facilitate urban development at the human scale; limit noise intrusion below levels accepted by communities; and be safe for people and their property. 
(3) In the economy: be financially affordable in each generation; be designed and operated to maximize economic efficiency and minimize economic costs; and help support a strong, vibrant and diverse economy.

The Center for Sustainable Transportation (CST, 2003; Jeon and Amekudzi, 2005, P6) specified sustainable transportation system this way:

(1) Allows the basic access needs of individuals and societies to be met safely and in a manner consistent with human and ecosystem health, and with equity within and between generations;

(2) Is affordable, operates efficiently, offers choice of transport mode, and supports a vibrant economy;

(3) Limits emissions and waste within the planet ability to absorb them, minimizes consumption of nonrenewable resources, reuses and recycles its components, and minimizes the use of land and the production of noise.

In view of the special focus on green engineering that employs pollution prevention and industrial ecology, some strategic goals with an emphasis on the environment were given to achieve sustainable development. A relevant example was the U.S. Department of Transportation (USDOT, 2003; Jeon and Amekudzi, 2005, P4), which showed its qualitative statement on sustainability principles in 2003 as:

(1) Reduce the amount of transportation-related pollutants and greenhouse gases released; (2) reduce the adverse effects of siting, construction and operation of transportation facilities; (3) improve the sustainability and livability of communities through investments in transportation facilities; and (4) improve the natural environment and communities affected by DOT-owned facilities and equipment. 
In terms of environmentally sustainable transportation, the Environment Directorate of the Organization for Economic Cooperation and Development (OECD, 1999; Jeon and Amekudzi, 2005, P6) adopted the following definition: "Transportation that does not endanger public health or ecosystems and that meets needs for access consistent with use of renewable resources at below their rates of regeneration; and use of nonrenewable resources below the rates of development of renewable substitutes."

A wide range of viewpoints on the definition of transportation system sustainability clearly exists, and corresponding definitions tend to have different emphases. Even descriptive sustainability principles, which were specified for capturing progress in transportation operations and programs, seem to be agency-dependent. However, a great degree of commonality exists as well, for instance that progress must occur with a continuous and dynamic balance between the three dimensions-economic development, environmental preservation, and social development—called the three pillars of sustainability. According to the mission statements of various DOTs in the United States, the concept of sustainability in transportation systems involves the attributes of system effectiveness and efficiency, and system impacts on the economy, environment, and society (Mihyeon Jeon and Amekudzi, 2005). Thus, it is important to incorporate all three pillars of sustainability with their respective stakeholders. Generally, social aspects indicate that all individual and societal transportation needs should be met in a manner consistent with human and ecosystem health, with equity within and between generations. The economic aspect captures the attributes of affordability, efficiency, and cost-effectiveness in a transportation system that supports a vibrant economy. The environmental aspect is related to protection, preservation, and enhancement of the existing environment by limiting transportation emissions and wastes, and by minimizing resource consumption. The public, government officials, and resource agencies or environmental advocacy groups are the stakeholders of the respective three pillars. 
A typical diagram indicating the relationship between pillars and interfaces of a general sustainability development concept is shown in Figure 2.1 (World Road Association, 2013).

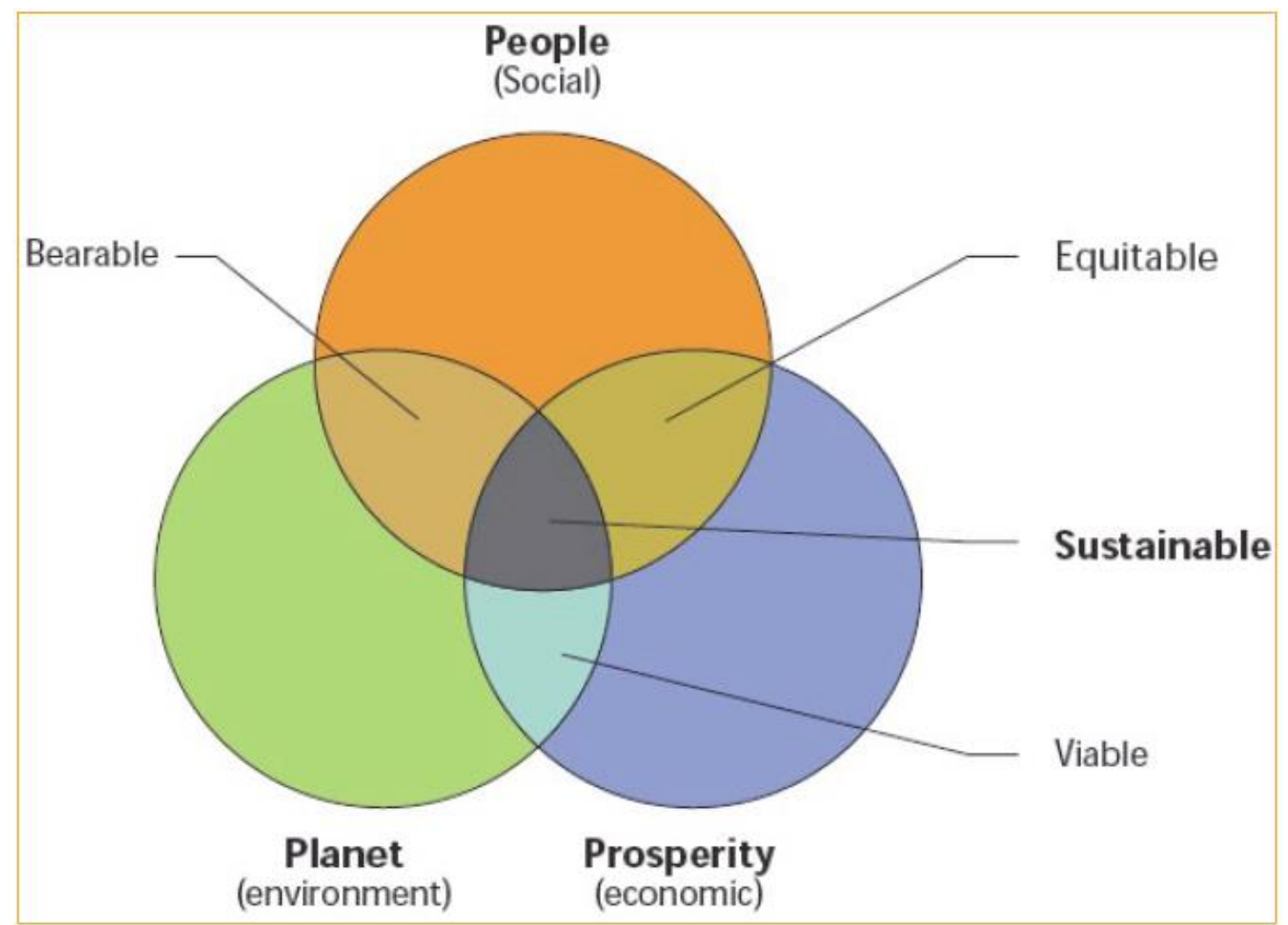

Figure 2.1 Three-dimensional framework of a sustainability development concept (World Road Association, 2013)

This three-pillar conceptual framework for sustainability development serves as a foundation and can be extended to other sustainability-based applications, such as in the field of winter roadway maintenance, as shown in Figure 2.2 (Shi, 2010). 


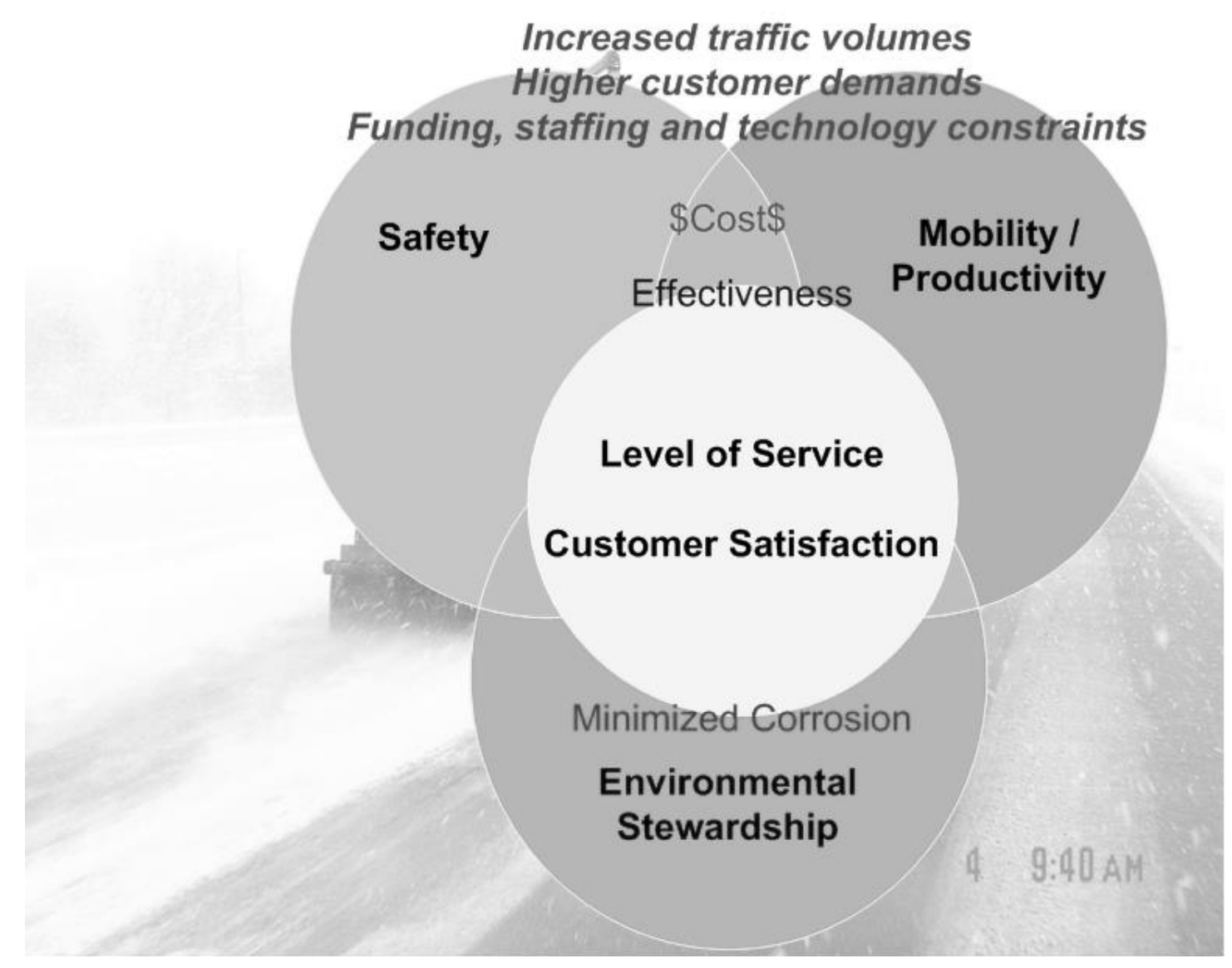

Figure 2.2 The concept of sustainable winter roadway maintenance (Shi, 2010)

\subsection{Highway Winter Maintenance: Current Practices}

There is growing research interest in how to maximize the advantages of using road salt deicers for winter road maintenance and reduce resultant negative impacts to the surrounding environment. Every year tons of road salt are applied to road surfaces to depress the freezing point of the snow-salt mixture, according to the requirement of the adopted salt's freezing temperature, and both anti-icing and pre-wetting are popular application strategies.

Anti-icing and pre-wetting chemicals have environmental impacts similar to deicing and sanding treatments; all have negative impacts on the receiving roadside soil, water bodies, aquatic biota, and vegetation through snowmelt runoff, infiltration, and wind (Todd and Kaltenecker, 2012; Perera et al., 2013). However, by using liquid materials, anti-icing and pre-wetting can help to reduce application rates and material usage, and thus reduce the 
detrimental impact to the environment. So far, few studies have tried to directly compare the environmental impact of liquid and solid snow- and ice-control products due to the numerous unquantifiable parameters in the receiving environment. It is recognized, however, that liquid chemicals are more concentrated at the beginning of application, and as time goes on, their influence weakens quickly through dilution and runoff. Solid chemicals can maintain a high level of concentration even after a certain period of application (e.g., $60 \mathrm{~min}$ ) due to the slow release process, and the retention of solid materials causes the surroundings to be affected for a longer time.

In terms of the adverse impacts of road salts, selection of alternatives for winter maintenance operations is always one of the primary directions. Many factors must be taken into account when selecting snow- and ice-control products, including lowest melting temperature, cost, availability, and environmental impacts (MPCA, 2008). O'Keefe and Shi (2006) listed some specifications developed by the Pacific Northwest Snowfighters Association (PNSA) to provide guidance for maintenance agencies in the selection of snowand ice-control chemicals. Constituent limits in parts per million (ppm) of chemical products, the required analyses for liquid products, and additional analyses for new chemical products were summarized in this study. Fay and Shi (2012) provided a comparison table to identify the defined heavy metals of interest and their total allowable limits in snow- and ice-control products specified by the Colorado DOT and PNSA. A series of performance evaluation methods was also developed to assist in the selection of snow-removal materials from environmentally sustainable or anti-corrosion perspectives (Shi et al., 2012, 2013). For example, Shi et al. (2014) presented a comprehensive and quantitative evaluation method for the chemicals used by Idaho DOT to identify the most sustainable materials by using the laboratory and field test data and reasonable assumptions. Muthumani et al. (2014) developed a laboratory oratory test that could correlate the field test results with information from 
practitioner interviews to better simulate anti-icing chemical performance. Based on these study results and practical evaluation, researchers have established that numerous products have been adopted for anti-icing and pre-wetting, in addition to traditional road salts. These products include a number of organic-based alternatives and agricultural byproducts derived from corn, beets, and grains, such as acetates (e.g., calcium magnesium acetate and potassium acetate), glycols, formates (e.g., sodium formate and potassium formate), particularly for some critical and environmentally sensitive areas (e.g., airline industry, bridges and other structures sensitive to chloride corrosion), profiting from their non-corrosive and biodegradable properties (Fay and Shi, 2012; Fu et al., 2012).

\section{$\underline{2.3 \text { Complexities and Caveats in the LCSA of Road Salt }}$}

Currently, there are considerable challenges in the quantification or estimation of the performance and impacts of road salt in a given region and the comprehensive LCSA of road salt for informed decision-making. Assumptions usually must be made in order to bridge the knowledge gaps in certain aspects related to the economic, environmental, and social impacts of road salt application. The potential sources of such complexities in the LCSA study of road salt (or other snow- and ice-control products) include, but are not limited to, the following issues.

First, the indirect implications of environmental footprints, costs, or benefits of road salt, which can be considered "ripple effects," create the need to define the boundary and time scale of analysis and select the appropriate temporal and spatial resolution for an LCSA study. For instance, the application of road salt on winter pavement can induce a higher risk of premature failure of concrete bridge decks, asphalt pavements, and motor vehicles, leading to the need for more frequent rehabilitation or repair activities, and to related traffic congestion in the case of infrastructure repair. This, in turn, causes a larger environmental footprint in connection with energy consumption, resource use, emissions, water pollution, 
etc., as well as indirect or secondary costs. To facilitate a LCSA, it is necessary to define the boundary of the analysis to focus on the major considerations. In addition, chlorides are known to be conservative in the environment. The application of road salt in many scenarios may pose little risk to the adjacent water bodies due to low acute concentrations observed, but pose significant risk to water bodies over the longer term (e.g., accumulation over decades). It is thus necessary to define the time scale of the analysis to facilitate the impact assessment.

Second, the cost, performance, and impacts of road salt application can be regionalized, localized, or site-specific, whereas the current LCSA typically adopts general values that overly simplify them. For example, numerous studies have reported environmental risks of deicers, indicating that the actual effects are highly site-specific and depend on the variety of traffic, the density of road networks, the climatic, soil, hydrological, and vegetation characteristics of the site, the type and amount of products applied, etc. (Fay and Shi, 2012). Consequently, reliable data are always lacking for quantitative studies. Even though available data could be adopted either from laboratory and field testing or from historical records and literature review, they may not be applicable for individual site conditions.

Third, many of the processes underlying the cost, performance, and impacts of road salt application are stochastic in nature, whereas current approaches for assessment are typically deterministic. For instance, the effect of salt-laden stormwater runoff from roads on an adjacent river or stream is partly influenced by flow rate and by precipitation during the current year and period. The fate and transport of sodium chloride and other additives in road salt can be very complicated, in light of the inherently site-specific and stochastic nature of the underlying processes and their interactions. In other words, no universal or deterministic model can be employed to reliably predict the level of impact due to road salt on the receiving roadside soil, water bodies, aquatic biota, and vegetation, and on human health. 
Finally, the fate and transport of road salt in the environment and the deterioration caused to the natural environment or to assets are poorly understood, let alone quantifiable. There remains a lack of effective correlation between the data obtained from current laboratory methods employed to assess the environmental impacts of deicers (e.g., aquatic toxicity of road salt) and their actual field impacts.

These complexities and caveats in the LCSA study of road salt illustrate the challenges in addressing sustainability assessment. As such, the next chapter presents a preliminary LCSA framework for evaluating road salt, which serves as a first step in the direction of sorting out the complexities, summarizing the key factors, and establishing a path for further improvement. 


\section{CHAPTER 3. METHODOLOGY - CONCEPTS OF LIFE CYCLE SUSTAINABILITY ASSESSMENT}

Life cycle sustainability assessment (LCSA) represents a new philosophy that has been widely discussed in recent years (Zamagni, 2012). Based on the definition in the context of sustainable development, the "triple bottom line" or the "three pillars" mode forms the basis of expression for LCSA in its measurement. This can be overly simplified as a linear equation, as follows:

$$
\mathrm{LCSA}=\mathrm{LCC}+\mathrm{LCA}+\mathrm{SLCA}
$$

where LCC denotes life cycle costing, LCA denotes environmental life cycle assessment, and SLCA denotes societal or social life cycle assessment. These categories respond to the economic, environmental, and social aspects of sustainability assessment, respectively, and jointly constitute the systematic structure of LCSA (Zamagni, 2012; Kloepffer, 2008).

Life cycle costing captures the economic effects of an industrial product or activity throughout its life cycle stages. Usually LCC starts with calculating the direct cost from extraction of resources, production, and usage of the product, to the cost management of product reuse, recycling, and disposal. Benefits accrued during any stage of the life cycle can be considered as a negative cost. Woodward defined the life cycle cost of an industrial product or activity as "the sum of all funds expended in support of the item from its conception and fabrication through its operation to the end of its useful life" (Woodward, 1997, P2). Harvey (1976) proposed a general LCC procedure summarized in Figure 3.1, in which Define the cost elements of interest entails the estimation of the direct cost that occurs during the service life of an industrial product or activity; Define the cost structure to be used entails the grouping of costs to identify potential trade-offs in the optimization of LCC; Establish the cost estimating relationships entails a mathematical expression that estimates the cost of an industrial product or activity as a function of different variables; and Establish 
the method of LCC formulation entails the process to finalize an appropriate approach to evaluate the life cycle cost of an industrial product or activity.

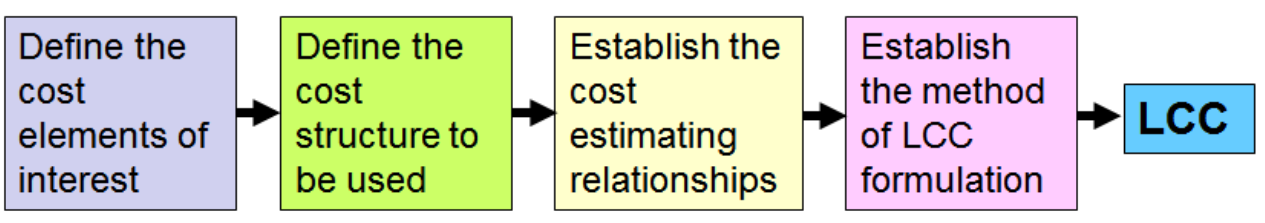

Figure 3.1 Harvey’s LCC procedure (Harvey, 1976; Woodward, 1997)

Environmental life cycle assessment (LCA) was developed as an analytical tool to assess the environmental impacts of an industrial product or activity. It was defined as " $a$ methodological framework for estimating and assessing the environmental impacts attributable to the life cycle of a product”" (Rebitzer et al., 2004). The International Standards Organization (ISO) initiated a global standardization process of LCA, including the development of four standards (goal and scope definition, inventory analysis, impact assessment, and interpretation), as well as a definition and basic requirements, as shown in Figure 3.2. The typical environmental impact categories include energy consumption, resource use, emissions (related to climate change, ozone layer depletion, acidification, eutrophication, etc.), toxicity, water, and waste.

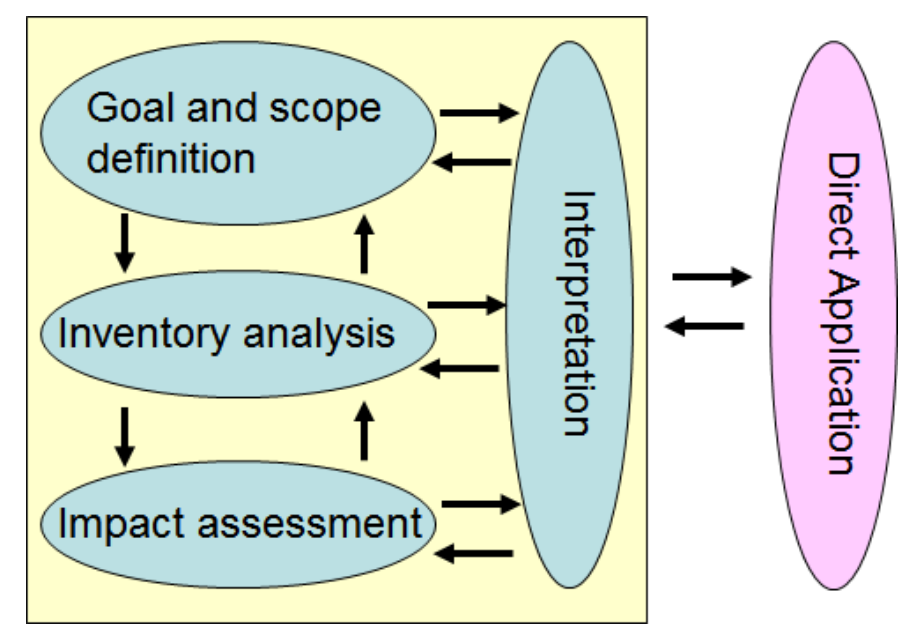

Figure 3.2 LCA framework based on the ISO 14040 standard 
Social life cycle assessment (SLCA) focuses on the social impacts of an industrial product or activity, specifically on the societal aspect of life cycle sustainability (Jorgenen et al., 2010; Jorgenson et al., 2012). This assessment category differs from its precursor, Social Impact Assessment (SIA). Even though SIA also aims to examine the social impacts of industrial products or activities, impacts across a whole life cycle are generally not included in its analysis. In contrast, SLCA can be defined as an aggregation of all phases of SIA in a product's life cycle (Fan et al., 2015). With a research focus on the effects of activities on humans, SLCA faces a major challenge in quantifying the social impacts of the particular system under assessment. Dreyer et al. (2006) presented a SLCA approach to standardize and quantify the social impacts as specific numbers by using scorecards, and later further improved the approach with more details and specifics for social issues and location. However, the method requires site-specific data that may not be readily accessible. Jorgensen et al. (2012) considered the most important part of SLCA to be obtaining available data and thus recommended conducting the SLCA with generic data, such as those from national censuses or public surveys. In 2006, a series of socioeconomic indicators were introduced for the application of SLCA, including human rights, labor practices, decent working conditions, and product responsibilities. These factors are directly affiliated with a stakeholder of the corresponding product (Grießhammer et al., 2006). The indicators affiliated with the stakeholders in the life cycle of a product or activity tend to provide the assessment of midpoint (e.g., worker, consumer, local community, society, and value chain actors) (see Figure 3.3).

As regards the working procedures and impacts of using road salt in WRM operations, the three branches just discussed are all embodied in WRM activities and they are interrelated. The next section will provide a brief discussion on the complexities and caveats 
in the LCSA of road salt; its aim is to help agencies achieve the goal of this type of assessment from economic, environmental, and social aspects.

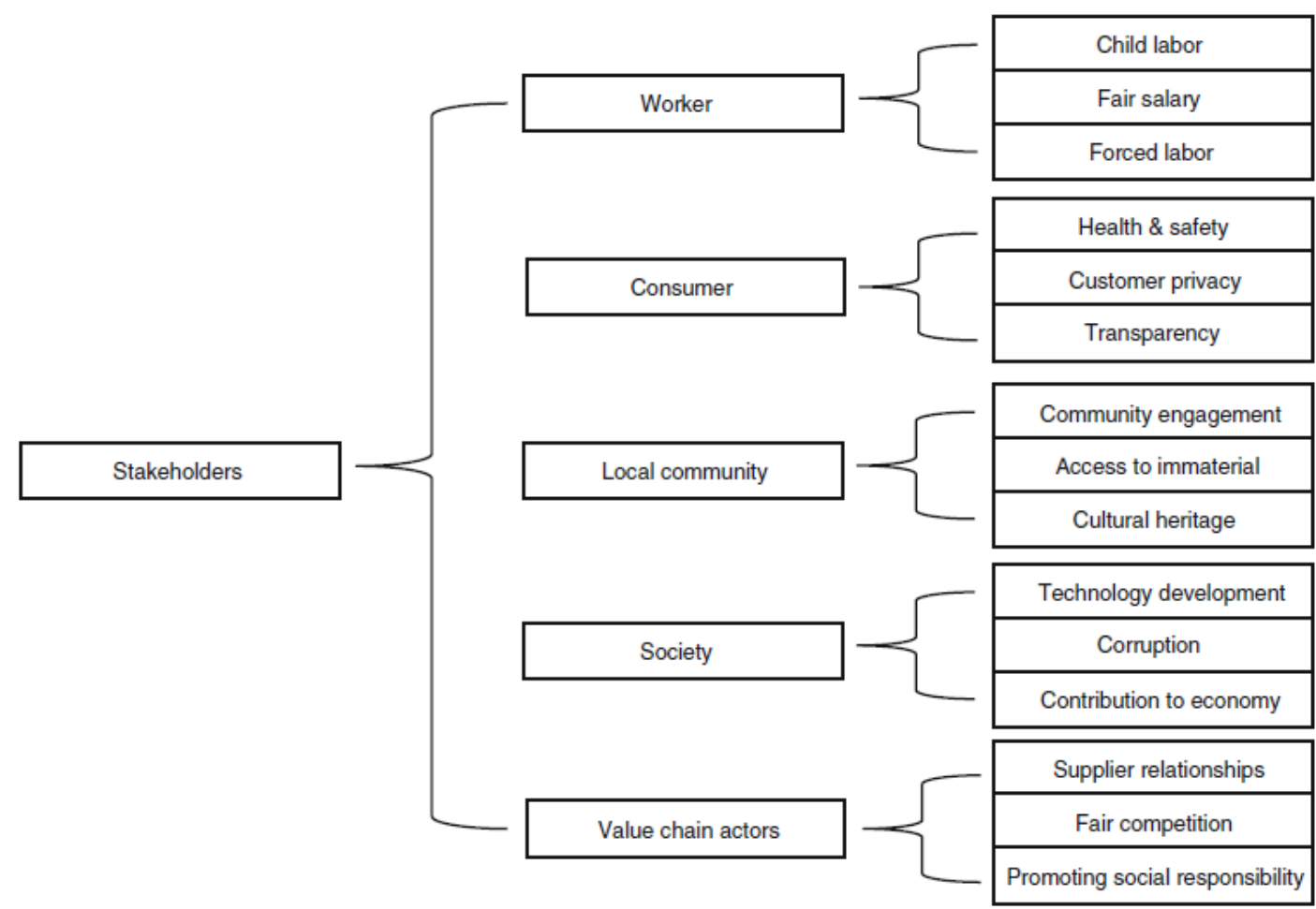

Figure 3.3 Five simplified stakeholder categories in the production system, according to the guideline for SLCA (Fan et al., 2015) 


\section{CHAPTER 4. A PRELIMINARY LCSA FRAMEWORK OF ROAD SALT}

This chapter provides an anatomy of the life cycle costing (LCC), environmental life cycle assessment (LCA), and social life cycle assessment (SLCA) branches of the integrated life cycle sustainability assessment (LCSA) framework for road salt used in winter road maintenance (WRM) operations. We place the focus on factors, components, and actions that should be considered in each branch, as well as the relationships among these concepts in the LCSA system.

\subsection{LCC Framework}

The LCC framework of road salt considers the following factors and components: capital and annual costs, disposal cost, life of assets, and discount rate, for the period under analysis. The costs may include those to the roadway agency and those to the roadway users. Once the expenditure stream is developed as a function of time, the net present value or annualized value of the road salt for snow and ice control can be calculated. The LCC can take either a deterministic or a probabilistic approach, the latter of which is a more realistic representation of the actual situation, because most of the input factors for LCC feature some level of uncertainty and would be better characterized by a statistical distribution than a single value.

Generally, capital and annual costs include the costs of manufacturing and storage (e.g., raw material extraction, land use, anti-caking treatment, ventilation, and packaging), transportation (e.g., from factory to DOT salt storage shed), implementation (e.g., application 
of road salt for anti-icing, deicing, or pre-wetting practice), training (e.g., for staff managing, handling and applying the road salt), equipment, and labor. Note that the benefits accrued from the application of road salt in terms of improved traveler safety and mobility, reduced travel cost, and fuel savings (Ye et al., 2013; Usman et al., 2012; Shahdah and Fu, 2010) can be considered negative costs under the implementation category.

Disposal cost usually does not occur until the end of the service life of an asset. For the LCC of road salt, the disposal cost of the salt itself is typically negligible, since salt is typically not recovered from the environment once it is applied to the pavement for snow and ice control. Instead, the disposal cost of motor vehicles and transportation infrastructure may be considered in the LCC framework, and so is the life of these assets, which is affected by their exposure to the road salt. Disposal cost may include the costs of demolishing, transportation (to the disposal site), landfill, and labor, and could be minimized with best practices in recycling and reuse of the materials.

For LCC, the dollar values of all the cost and benefit components occurring in future years should be expressed in current year dollars, that is, present value. For analysis of costs and benefits directly or indirectly related to road salt, the discount rate could be considered within the range of $3 \%$ to over $20 \%$, depending on the market needs and supplies, organizations, and technologies (Woodward, 1997). 


\subsection{LCA Framework}

Drawing upon the published literature, environmental LCA can be iteratively described by the following four categories: goal and scope definition, life cycle inventory analysis, impact assessment, and interpretation.

\subsubsection{Goal and Scope}

For road salt, the goal of LCA is to account for the negative impacts that its life cycle may have on the natural environment, including surface water, groundwater, air, soil, vegetation, wildlife, etc. As such, the results of LCA can be used to aid in best practices by agencies to minimize negative environmental footprints and to address environmental justice and ecological issues.

As to scope or domain of analysis, an LCA considers both the direct impacts of road salt on the receiving environment and the indirect environmental impacts (e.g., those induced by the premature failure of corroded equipment or transportation infrastructure). The environmental benefits derived from the use of road salt are considered as well, including those from the avoidance of traffic accidents and delays, translated to reduced emissions and fuel consumption (Min, 2015). The scope can vary greatly as a function of time duration, geographic location, local priorities of environmental stewardship, technological context of salt application and infrastructure preservation, and possibly political and cultural constraints. Thus, it is necessary to clearly define the scope of LCA before comparing different alternatives or different studies against each other. 


\subsubsection{Life Cycle Inventory}

Life cycle inventory (LCI) is a process employed to define the inputs and outputs of an industrial product or industrial activity when interacting with the environment, and to collect data regarding the resultant environmental burden (ISO, 1998). The inputs of road salt in the LCI analysis mainly include the raw materials and energy consumed during the course of manufacturing, storage, transportation, implementation, and disposal. Raw materials may include not only the sodium chloride mineral and other additives in the road salt for WRM, but also the materials for preservation or rehabilitation of transportation infrastructure and the salt remover, anticorrosion coating, or corrosion inhibitor for equipment preservation. The outputs may include greenhouse gas emissions and other airborne pollutants, solid wastes (e.g., deteriorated vehicle parts, asphalt pavement, and concrete bridge deck), traffic noise (due to salt-deteriorated wear of pavement surface), and liquid effluents (e.g., salt-laden stormwater runoff) discharged into the receiving environment.

\subsubsection{Life Cycle Impact Assessment}

Life cycle impact assessment (LCIA) works to translate LCI results into potential environmental impacts; the major concerns include human health, the natural environment, natural resources, and artificial environment (Hauschild et al., 2005). The widely accepted four steps of LCIA include the selection of impact categories and classification, characterization, normalization, and valuation (ISO, 2000). For road salt, the main environmental impact categories include chronic toxicity of sodium chloride and other additives to aquatic species and human beings; air/soil/vegetation/water pollution due to application of road salt, air/soil/vegetation/water and noise pollution due to increased 
preservation or rehabilitation activities of transportation infrastructure, chronic deterioration of wildlife habitat, greenhouse gas emissions (a.k.a., global warming potential), energy consumption, and solid waste. During the characterization step, the environmental impact in each category is quantified into scores or equivalent values (e.g., converting the greenhouse gas emissions into $\mathrm{kg} \mathrm{CO}_{2}$ equivalents). The quantification of environmental impacts can be highly variable and stochastic, depending on the geographical location, salt application process, and characteristics of the receiving environment. During the normalization step, the magnitude of these impact scores is normalized to the same scale that is applied to all the impact categories. During the valuation step, the relative importance of impact scores is evaluated by ranking or weighting factors.

\subsubsection{Interpretation}

The results of interpretation can help agencies understand the potential negative effects of road salt on the receiving environment and make environmentally conscious decisions, with local priorities and constraints in mind. The results can also provide support to optimize the previous three categories in an iterative process to revise the goal and scope, LCI, and LCIA until a final decision can be made, as shown in Figure 2.2.

\subsection{SLCA Framework}

The SLCA framework of road salt considers both the positive and negative impacts of using road salt for WRM operations. On the positive side, road salt use provides social benefits such as avoided traffic accidents and improved convenience due to the improved level of service on winter pavement. While difficult to monetize, improved convenience may 
be realized in the form of continued community services, reduced response time to emergencies, reduced traveler discomfort, and reduced wage loss associated with absence from work. Other social benefits may include increased worker opportunities and technology development, etc. listed in Figure 3.3.

On the negative side, road salt use has social implications: increased risk to human health; inconvenience associated with more inspections and rehabilitation of motor vehicles, equipment, and roadway infrastructure; and possible growth in social inequality. First, exceedances of the EPA water standard for chloride reportedly have been attributable to the use of road salt (Trowbridge et al., 2010). The conservative nature of sodium and chloride ions in the natural environment makes it difficult to remove them. Their concentration peaks during runoff or accumulation over the long term, along with their possible role in leaching other metals out of soil, can pose a health risk to human beings. Second, for assets exposed to road salt, their serviceability and durability are compromised, which necessitates more frequent inspection and rehabilitation (Li et al., 2013; Suraneni et al., 2016). Finally, underinvested and underserved communities are typically more vulnerable to environmental and infrastructure impacts posed by the use of road salt, due to lack of monetary resources, leading to social inequality induced by the use of road salt.

\section{$\underline{4.4 \text { Other Considerations }}$}

\subsection{Life of Assets}

The service life of motor vehicles and transportation infrastructure exposed to road salt can be estimated in terms of the physical life, technological life, economic life, and social 
and legal life of the asset (Ferry and Flanagan, 1991). Note that the resulting LCC, LCA, and SLCA with a longer service life prediction (e.g., over 50 years) is considerably different from a short-term prediction (e.g., less than 10 years). Decisions on the service life of these assets should be included in the LCSA framework (Stone, 1980).

\subsubsection{Uncertainties and Sensitivity Analysis}

Uncertainty is an inevitable factor to consider when implementing the LCSA of road salt (or other WRM products, technologies, or practices). For instance, uncertainties are inherent in the estimation of the discount rate in future years, in the dynamics of supply versus demand of road salt, in the deicer usage and frequency (as a function of policy, equipment innovations, climatic conditions, etc.), in the corrosion and environmental risks (as a function of the fate and transport of road salt and secondary pollutants), and in the safety and mobility benefits achieved from the application of road salt. In addition, the social impacts of applying road salt can vary greatly by location, cultural and societal heritage, regulatory practice, technologies, worker environment, etc. In the SLCA, most of the indicators are not easily identified and measured. Furthermore, in light of the limited data available from actual records or statistical analysis, necessary assumptions are often made during the analysis, and they add to the level of uncertainties.

To improve the reliability of the analysis results, it is desirable to conduct a sensitivity analysis of LCSA; that is, by examining how the outcome of LCSA would change by varying each input factor used in the assessment within a given range or a given statistical distribution. 


\subsubsection{Information and Feedback}

The efficacy of LCSA analysis of road salt largely depends on the information

collection and necessary feedback across the entire life cycle dimension of road salt.

Currently, there is a significant gap in the data needed to enable a quantitative or semi-

quantitative LCSA of road salt. The data on costs (and benefits), environmental impacts, and societal impacts need to be collected over a reasonably long duration (e.g., 40 years), from a diverse yet representative array of scenarios, and in a consistent and ideally standardized format. In this area, collaborative efforts are needed between roadway agencies and other stakeholder groups.

\subsection{The Relationships of LCC, LCA, and SLCA in the LCSA}

Life cycle sustainability assessment is a combination of LCC, LCA, and SLCA with some linear or nonlinear and static or dynamic features (Zamagni, 2012). This form of assessment integrates the impacts of all three pillars of sustainability through the analysis of LCC, LCA, and SLCA, and provides a reasonable approach to evaluating industrial products or activities from a life cycle perspective.

In previous research, Lee and Kirkpatrik (2001) wrote on the $10^{\text {th }}$ page, “The combined impacts, positive and negative, of the sets of measures as a whole, are likely to be more than the simple sum of the impacts of their constituent measures because of synergistic effects." Therefore, the LCSA of road salt has to be considered as a function of LCC, LCA, and SLCA rather than a linear sum of these three branches. Specifically, their mutual effects 
and interdependencies have become an important factor that determines the assessment results (see Figure 4.1).

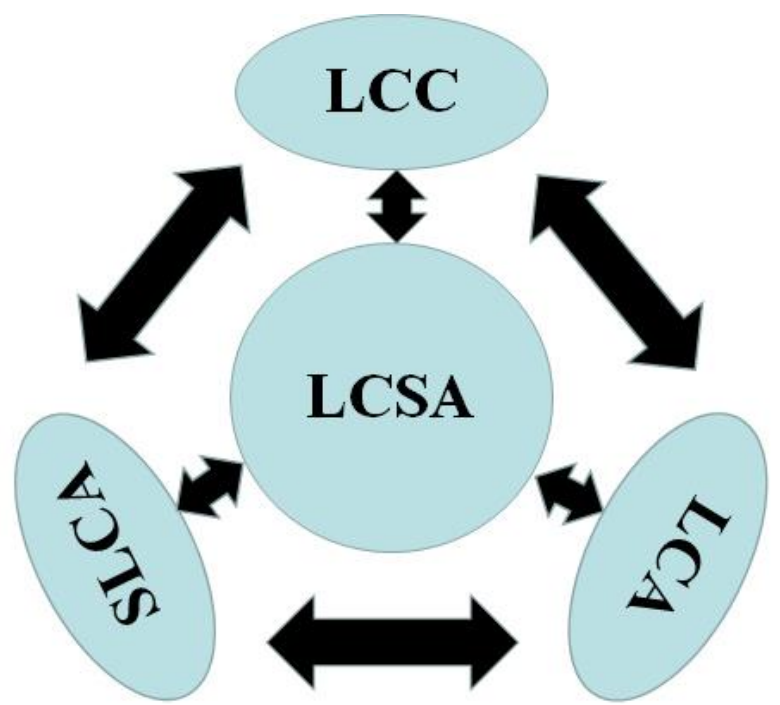

Figure 4.1 Interactions between LCC, LCA, SLCA, and LCSA

The expression of their relationships in the original linear equation (3.1) can be rewritten as:

$$
\mathrm{LCSA}=f(\mathrm{LCC}, \mathrm{LCA}, \mathrm{SLCA})
$$

where each of the functions of LCC, LCA, and SLCA can be expressed as a function of the other two branches, as shown below:

$$
\begin{aligned}
& \text { LCC }=f_{1}(\text { LCA }, \text { SLCA }) \\
& \text { LCA }=f_{2}(\text { LCC, SLCA }) \\
& \text { SLCA }=f_{3}(\text { LCC, LCA })
\end{aligned}
$$

Figure 4.2 illustrates the interactions between the LCC, LCA, and SLCA of road salt, which must be considered comprehensively in the LCSA process. For instance, vehicle corrosion and road infrastructure deterioration due to road salt can pose negative impacts to mainly economics and the natural environment. The soil pollution, vegetation deterioration, 
decreased water and air quality, and compromised wildlife habitat and human health due to road salt can have negative impacts mainly on the natural environment and human society. The safety and efficiency of the transportation system during winter weather can be enhanced by the appropriate use of road salt, which then positively impacts all three domains of sustainability: economic, social, and environmental. In other words, it is risky to conduct the LCC of road salt without conducting LCA and SLCA, since this type of isolated analysis may result in misinformed decisions that ignore the environmental and social impacts that cannot be readily monetized. Similarly, it is not a holistic or sustainable approach if one conducts the LCA or SLCA of road salt without accounting for the economic impacts.

Figure 4.3 provides a fishbone diagram for the preliminary LCSA framework of road salt for WRM operations, which can be used to enable more holistic and balanced decisions. Currently, the knowledge gaps in quantifying many of the cost, benefit, or impact items in each branch of the LCSA framework are significant and remain to be addressed in future research. Case studies and practitioner surveys are strongly recommended to help address the present lack of information. Furthermore, the interactions between LCC, LCA, and SLCA can further complicate the quantitative analysis under this LCSA framework. Nonetheless, we anticipate that the LCSA framework developed for road salt can be extended to other types of WRM products, technologies, and practices. 

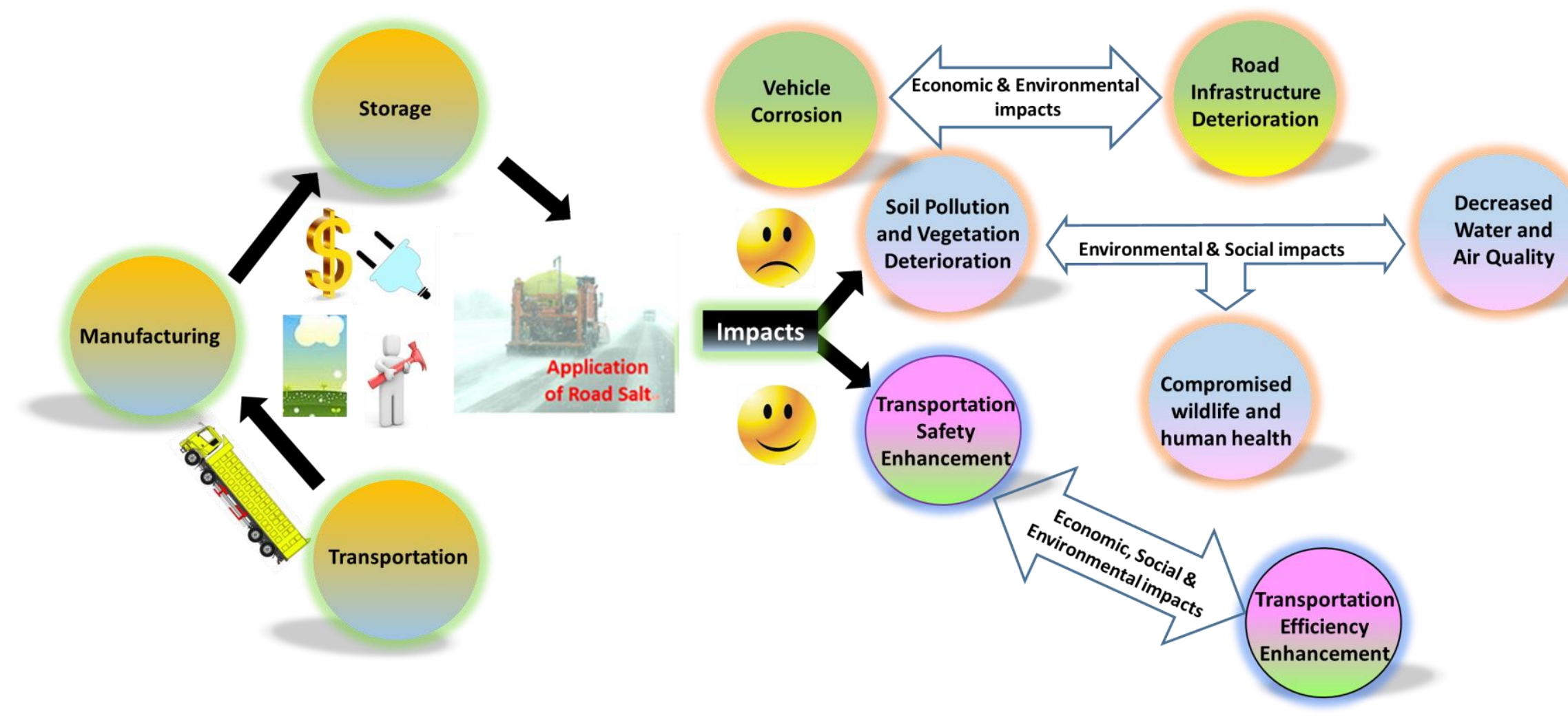

Figure 4.2 The interactions considered in the LCSA process 


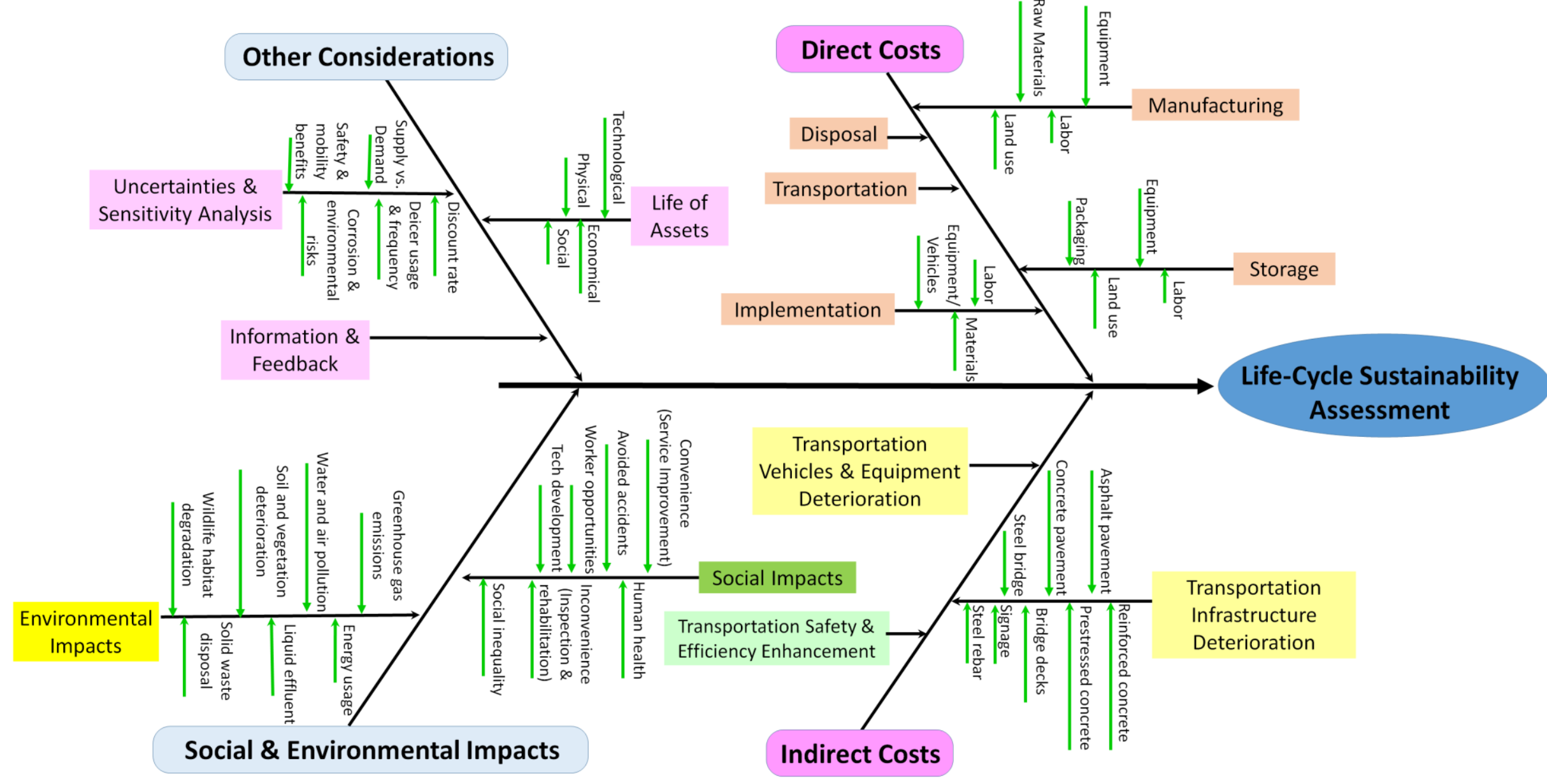

Figure 4.3 LCSA fishbone diagram of road salt used in WRM operations 


\section{CHAPTER 5. CONCLUSIONS}

In response to the growing interest in assessing the life cycle sustainability of winter road maintenance (WRM) operations, we presented through this report an initial exploration of the development of an integrated life cycle sustainability assessment (LCSA) framework for road salt, widely used in WRM programs. The LCSA framework aims to help produce a full picture of the impacts of each step in the use of road salt. The report began with a description of key concepts - life cycle costing (LCC), environmental life cycle assessment (LCA), and social life cycle assessment (SLCA) — that respond to the economic, environmental, and social aspects of sustainability assessment, respectively. This description was followed by a discussion of the complexities and caveats, including the indirect implications, of using road salt, the site-specific nature of cost, performance, and impacts of road salt application, the stochastic nature of underlying processes, and the poor understanding of many of the aspects. Subsequently, an anatomy of the LCC, LCA, and SLCA branches of the integrated LCSA framework for road salt used in WRM operations was provided. The interactions between LCC, LCA, and SLCA, and how to quantitatively characterize the indicators in each branch are recognized as knowledge gaps to be addressed in future research. 


\section{REFERENCES}

Corsi, S. R., Graczyk, D. J., Geis, S. W., Booth, N. L., and Richards, K. D. (2010). “A fresh look at road salt: Aquatic toxicity and water-quality impacts on local, regional, and national scales.” Environmental Science Technology, 44, 7376-7382.

CST (Center for Sustainable Transportation). (2003). "Transportation performance indicators." CSR, Toronto <www.cstctd.org>.

Dean, W. P., Sanford, B. J., Wright, M. R., and Evans, J. L. (2012). "Influence of deicers on the corrosion and fatigue behavior of 4140 steel." Journal of Materials Engineering and Performance, 21, 2340-2344.

Dreyer, L.C., Hauschild, M.Z., and Schierbeck, J., (2006). “A framework for social life cycle impact assessment." The International Journal of Life Cycle Assessment, 11, 88-97.

EEA (European Environment Agency). (2002). "Transport and environment reporting mechanism (TERM) 2002 — Paving the way for EU enlargement: Indicators of transport and environment integration Environmental Issues.” Copenhagen, Denmark.

European Commission (Energy, Environment and Sustainable Development Program,

Procedures for Recommending Optimal Sustainable Planning of European City Transport Systems (PROSPECTS). (2003). “Developing Sustainable Urban Land Use and Transport Strategies: Methodological guidebook."

Fan, Y., Wu, R., Chen, J., and Apul, D. (2015). “A review of social life cycle assessment methodologies." In Social Life Cycle Assessment. Springer, Singapore.

Fay, L., and Shi, X. (2012). "Environmental impacts of chemicals for snow and ice control: state of the knowledge." Water, Air, and Soil Pollution, 223, 2751-2770. 
Ferry, D.J.O., and Flanagan, R. (1991). "Life cycle costing a radical approach.” Construction Industry Research and Information Association. London, U.K.

Fitch, G. M., Smith, J. A., and Clarens, A. F. (2013). "Environmental life-cycle assessment of winter maintenance treatments for roadways." Journal of Transportation Engineering, $139,138-146$.

Fu, L., Omer, R., and Jiang, C. (2012). "Field test of organic deicers as pre-wetting and antiicing agents for winter road maintenance." Transportation Research Record: Journal of the Transportation Research Board, 2272(1), 130-135.

Grießhammer, R., Benoît, C., Dreyer, L. C., Flysjö, A., Manhart, A., Mazijn, B., ... , and Weidema, B. P. (2006). "Feasibility Study: Integration of Social Aspects into LCA.” Öko-Institut, Freiburg.

Harvey, G. (1976). "Life-cycle costing: A review of the technique.” Management Accounting, October, 343-347.

Hauschild, M., Jeswiet, J., and Alting, L. (2005). "From life cycle assessment to sustainable production: status and perspectives." CIRP Annals-Manufacturing Technology, 54, 1-21.

Hossain, S .K., Fu, L. and Lake, R. (2015). "Field evaluation of the performance of alternative deicers for winter maintenance of transportation facilities." Canadian Journal of Civil Engineering, 42(7), 437-448.

ISO. (1998). Environmental Management: Life Cycle Assessment: Goal and Scope Definition and Inventory Analysis: International Organization for Standardization (ISO) 14041: Geneva, Switzerland. 
ISO. (2000). Environmental Management: Life Cycle Assessment: Life Cycle Impact Assessment. International Organization for Standardization (ISO) 14042: Geneva, Switzerland.

Jorgenen, A., Finkbeiner, M., Jorgensen, M., and Hauschild, M. (2010). "Defining the baseline in social life cycle assessment." The International Journal of Life Cycle Assessment, 15, $376-384$.

Jorgenson, A., Dreyer, L., and Wangel, A. (2012). "Addressing the effect of social life cycle assessments." The International Journal of Life Cycle Assessment, 17, 828-839.

Kloepffer, W. (2008). "Life cycle sustainability assessment of products." The International Journal of Life Cycle Assessment, 13, 89-95.

Lee, N., and Kirkpatrik, C. (2001). "Methodologies for sustainability impact assessments of proposals for new trade agreements." Journal of Environmental Assessment Policy and Management, 3, 395-412.

Levelton Consultants. (2007). "Guidelines for the Selection of Snow and Ice Control Materials to Mitigate Environmental Impacts.” NCHRP Report, 577. National Research Council, Washington, D.C.

Li, Y., Fang, Y., Seeley, N., Jungwirth, S., Jackson, E., and Shi, X. (2013). “Corrosion by chloride deicers on highway maintenance equipment: Renewed perspective and laboratory investigation." Transportation Research Record: Journal of the Transportation Research Board, 2361, 106-113.

May, A. D., Karlstrom, A., Marler, N., Matthews, B., Minken, H., Monzon, A., ... \& Shepherd, S. (2003). "Developing Sustainable Urban Land Use and Transport Strategies-A Decision Makers' Guidebook.” Institute for Transport Studies, University of Leeds, Leeds. 
Mihelcic, J. R., Crittenden, J. C., Small, M. J., Shonnard, D. R., Hokanson, D. R., Zhang, Q., ..., and Schnoor, J. L. (2003). "Sustainability science and engineering: The emergence of a new metadiscipline." Environmental Science and Technology, 37(23), 5314-5324.

Mihyeon Jeon, C., and Amekudzi, A. (2005). “Addressing sustainability in transportation systems: definitions, indicators, and metrics.” Journal of Infrastructure Systems, 11(1), $31-50$.

Min, J. (2015). "Quantifying the Effects of Winter Weather and Road Maintenance on Emissions and Fuel Consumptions." A thesis presented to the University of Waterloo. Master of Applied Science in Civil Engineering, Waterloo, Ontario, Canada, 2015.

MPCA (Minnesota Pollution Control Agency, Fortin Consulting Inc., et al.). (2008). "Winter parking lot and sidewalk maintenance manual.” <http://www.pca.state.mn.us/index.php/view- document. html?gid=5491>

Muthumani, A., and Shi, X. (2016). "Effectiveness of liquid agricultural by-products and solid complex chlorides for snow and ice control." Journal of Cold Regions Engineering (in press).

Muthumani, A., Fay, L., Akin, M., Wang, S., Gong, J., and Shi, X. (2014). “Correlating laboratory and field tests for evaluation of deicing and anti-icing chemicals: A review of potential approaches." Cold Regions Science and Technology, 97, 21-32.

Nixon, W. A. (2012). "Measuring sustainability in winter operations.” Transportation Research Board Annual Meeting, Washington, D.C.

OECD (Organization for Economic Cooperation and Development). (1999). "Indicators for the integration of environmental concerns into transport policies." Environment Directorate, Paris. 
O’Keefe, K., and Shi, X. (2006). “Anti-icing and pre-wetting: Improved methods for winter highway maintenance in North America." In Proceedings of the Transportation Research Board, Annual Meeting, 22-26.

Pan, T., He, X., and Shi, X. (2008). "Laboratory investigation of acetate-based deicing/anti-icing agents deteriorating airfield asphalt concrete.” Asphalt Paving Technology-Proceedings, $77,773$.

Perera, N., Gharabaghi, B., and Howard, K. (2013). "Groundwater chloride response in the Highland Creek watershed due to road salt application: A re-assessment after 20years." Journal of Hydrology, 479, 159-168.

Rebitzer, G., Ekvall, T., Frischknecht, R., Hunkeler, D., Norris, G., Rydberg, T., ... \& Pennington, D. W. (2004). "Life cycle assessment: Part 1: Framework, goal and scope definition, inventory analysis, and applications.” Environment international, 30(5), 701 720.

Shahdah, U., and Fu, L. (2010). "Quantifying the mobility benefits of winter road maintenanceA simulation based analysis." In TRB $89^{\text {th }}$ Annual Meeting Compendium of Papers (DVD), Washington, D.C.

Shi, X. (2010). "Winter road maintenance: Best practices, emerging challenges and research needs.” Journal of Public Works and Infrastructure, 2(4), 318-326.

Shi, X., Fay, L., Yang, Z., Nguyen, T. A., and Liu, Y. (2009). "Corrosion of deicers to metals in transportation infrastructure: introduction and recent developments." Corrosion Reviews, $27,23-52$. 
Shi, X., Fay, L., Peterson, M. M., and Yang, Z. (2010). "Freeze-thaw damage and chemical change of a Portland cement concrete in the presence of diluted deicers." Materials and Structures, 43(7), 933-946.

Shi, X., Fortune, K., Fay, L., Smithlin, R., Cross, D., Yang, Z., and Wu, J. (2012). "Longevity of corrosion inhibitors and performance of anti-icing products after pavement application: A case study." Cold Regions Science and Technology, 83, 89-97.

Shi, X., Veneziano, D., Xie, N., and Gong, J. (2013). "Use of chloride-based ice control products for sustainable winter maintenance: A balanced perspective.” Cold Regions Science and Technology, 86, 104-112.

Shi, X., Jungwirth, S., Akin, M., Wright, R., Fay, L., Veneziano, D., Zhang, Y., Gong, J., and Ye, Z. (2014). "Evaluating snow and ice control chemicals for environmentally sustainable highway maintenance operations." ASCE Journal of Transportation Engineering, 140(11), 05014005

Stone, P. A. (1980). Building Design Evaluation Cost in Use. University Printing House, Cambridge, U.K.

Suraneni, P., Salgado, N., Carolan, H., Li, C., Azad, V., Isgor, B., ..., and Weiss, J. (2016). "Mitigation of deicer damage in concrete pavements caused by calcium oxychloride formation - Use of ground lightweight aggregates.” In Proc Int RILEM Conf on Materials, Systems and Structures in Civil Engineering, Denmark.

Sustainable Transportation Indicators Subcommittee of the Transportation Research Board (ADD40) (2008). “Sustainable Transportation Indicators.” 2009 Transportation Research Board Annual Meeting. <http://uportal.isfahan.ir> 
Todd, A. K., and Kaltenecker, M. G. (2012). "Warm season chloride concentrations in stream habitats of freshwater mussel species at risk." Environmental Pollution, 171, 199-206. Transport Canada. (2001). “Sustainable development strategy 2001-2003.” Ottawa: Transport Canada, <http://www.tc.gc.ca/programs/environment/sd/strategy0103/action plan.htm> Transportation Association of Canada. (1999). "Urban transportation indicators." Ottawa, <http://www.tac-atc.ca/english/productsandservices/ui/exec.asp>

Trowbridge, P. R., Kahl, J. S., Sassan, D. A., Heath, D. L., and Walsh, E. M. (2010). "Relating road salt to exceedances of the water quality standard for chloride in New Hampshire streams." Environmental Science and Technology, 44(13), 4903-4909.

USDOT (U.S. Department of Transportation). (2003). "Performance Rep. No. 2004 Performance Plan.” Washington, D.C., <http://www.dot.gov/PerfPlan2004/index.html>

Usman, T., Fu, L., and Miranda-Moreno, L. F. (2012). “A disaggregate model for quantifying the safety effects of winter road maintenance activities at an operational level." Accident Analysis and Prevention, 48, 368-378.

Woodward, D. (1997). "Life cycle costing - Theory, information acquisition and application." International Journal of Project Management, 15, 335-344.

World Commission on Environment and Development. (1987). Brundtland report, "Our common future."

World Road Association. (2013). Technical Committee B.5. "Sustainable development and winter service.” Technical Report, <http://www.piarc.org/en/order-library/19367-enSustainable\%20developmen\%20and\%20winter\%20service.htm>

Xie, N., Shi, X., and Zhang, Y. (2016). "Impacts of potassium acetate and sodium-chloride deicers on concrete." Journal of Materials in Civil Engineering, 04016229. 
Ye, Z., Veneziano, D., and Shi, X. (2013). "Estimating statewide benefits of winter maintenance operations." Transportation Research Record: Journal of the Transportation Research Board, (2329), 17-23.

Zamagni, A. (2012). "Life cycle sustainability assessment." The International Journal of Life Cycle Assessment, 17, 373-376. 